\title{
Correction to: Engineering Fluid Mechanics
}

\section{Correction to: \\ H. Song, Engineering Fluid Mechanics, https://doi.org/10.1007/978-981-13-0173-5}

The original version of the book is inadvertently published with some errors in equations, figures, and tables. We have listed them below and the book has been updated with the changes.

\section{List of Corrections:}

Page 14, Table 1.5: add unit "Pa" for bulk modulus in the heading of Table 1.5. Namely, Table 1.5 Water's bulk modulus at different temperature and pressure, Pa. Page 31, Sect. 2.4.1, $1 \mathrm{~atm}=760 \mathrm{mmHg}=101.325 \mathrm{kPa}=1.01325 \times 10^{5} \mathrm{~Pa}\left(\right.$ not $\left.1.1013 \times 10^{5} \mathrm{~Pa}\right)$. Page 39, Table 2.1. The moment of inertia of a semicircle evaluated about its centroid is as follows: $I_{c}=\frac{1}{16}\left(\frac{\pi}{8}-\frac{8}{9 \pi}\right) d^{4}$. The entry in Table 2.1 is missing the final factor of $d^{4}$.

Page 62, Example 3.4. The solution assumes steady incompressible flow, so the phrase "assuming steady incompressible flow" should be added.

Page 83, Sect. 3.9.1, line 5: change " $v_{1}$ " and " $v_{2}$ " to " $u_{1}$ " and " $u_{2}$ ", respectively. Page 85, Fig. 3.25: add $x$ and $y$ axes.

\footnotetext{
The updated version of the book can be found at https://doi.org/10.1007/978-981-13-0173-5

(C) Metallurgical Industry Press, Beijing and Springer Nature Singapore Pte Ltd. 2020 


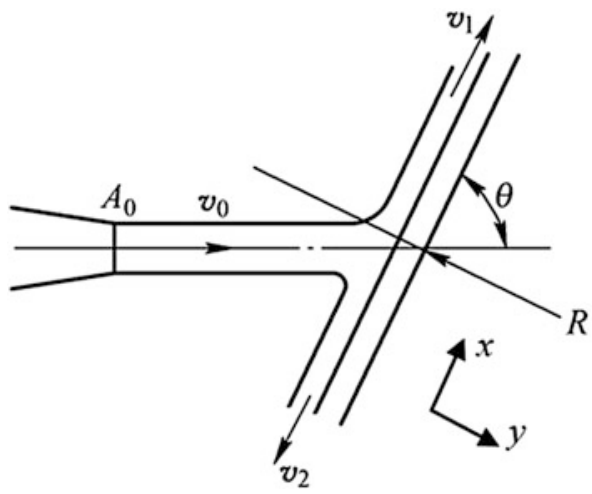

Page 87, Sect. 3.9.2, the equation should be $\frac{\mathrm{d} M}{\mathrm{~d} t}=\rho Q v=\rho A v^{2}$.

Page 109, Eq. (4.10), the second equal sign should be a minus sign, thus: $\tau_{0}=-\frac{\Delta p R}{2 l}$.

Page 120, Sect. 4.5.2, add the following sentence for Region IV.

Region IV: The range of Reynolds number is $22.2\left(\frac{d}{\Delta}\right)^{\frac{8}{7}}<\operatorname{Re}<597\left(\frac{d}{\Delta}\right)^{\frac{9}{8}}$.

Page 121, Sect. 4.5.2, add the following sentence for Region V.

Region V: The range of Reynolds number is $\operatorname{Re}>597\left(\frac{d}{\Delta}\right)^{\frac{9}{8}}$.

Page 126, Sect. 4.7.2, line 1: the position of the change from transition flow (not laminar flow) to turbulent flow is called transitional point $x_{c}$.

Page 127, Fig. 4.13: add (a) and (b).

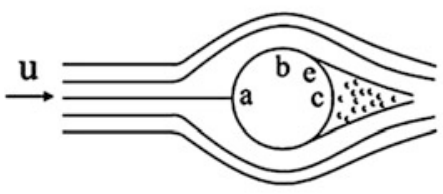

(a)

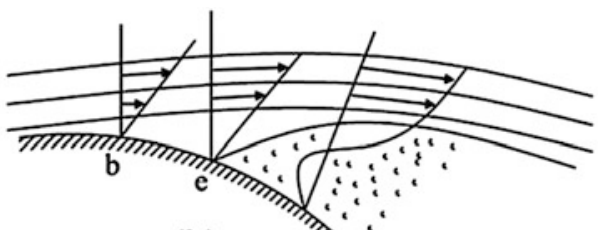

(b)

Page 141, 4.19: add the condition, $d_{2}=100 \mathrm{~mm}$.

Page 148, Table 5.1, add the units $\left[\mathrm{s} / \mathrm{m}^{1 / 3}\right]$ to the header for Manning's $n$. 
Page 175, Eq. (6.10),

$$
J=\frac{h_{w}}{l}=\frac{h_{1}-h_{2}}{l}=\frac{\left(z_{1}-z_{2}\right)+\frac{p_{1}-p_{2}}{\rho g}}{l}
$$

$=\frac{l+\frac{p_{1}-p_{2}}{\rho g}}{l}=1+\frac{p_{1}-p_{2}}{l \rho g}$ without the comma ", ,".

Page 180, Fig. 6.4:

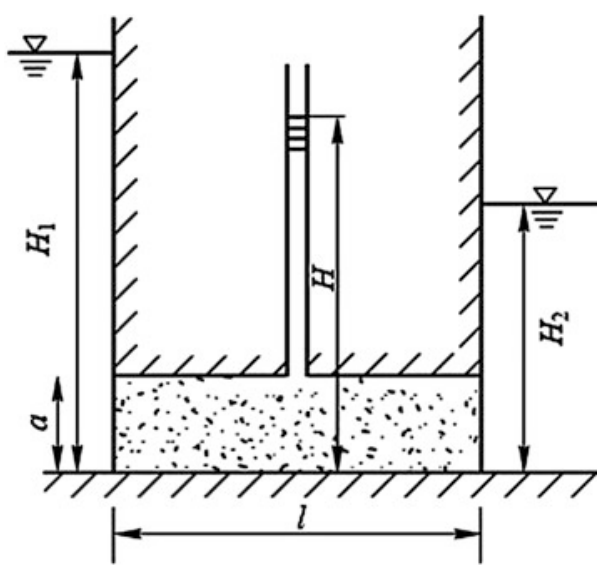

Page 186, Eq. (6.35) should be

$$
\frac{\partial\left(\rho v_{x}\right)}{\partial x}+\frac{\partial\left(\rho v_{y}\right)}{\partial y}+\frac{\partial\left(\rho v_{z}\right)}{\partial z}=-\frac{K}{\mu} \rho_{\mathrm{a}}\left(\frac{\partial^{2} p}{\partial x^{2}}+\frac{\partial^{2} p}{\partial y^{2}}+\frac{\partial^{2} p}{\partial z^{2}}\right)
$$

Page 189, Example 6.2: the viscosity of the liquid should be $1 \times 10^{-3} \mathrm{~Pa} \cdot \mathrm{s}$ (not $\left.1 \times 10^{3} \mathrm{~Pa} \cdot \mathrm{s}\right)$.

Page 190, Solution of the Example 6.2: it should be $\mu=1 \times 10^{-3} \mathrm{~Pa} \cdot \mathrm{s}$ and $K=\frac{q \mu L}{A \Delta p}=\frac{0.125 \times 10^{-6} \times 10^{-3} \times 0.05}{3.14 \times 0.01^{2} \times 20924.96}=0.95 D$. 


\section{Appendix}

Chap. 1, 1.3: $\tau=145.8 \mathrm{mPa}$

Chap. 2, 2.13: $h_{D}=1.67 \mathrm{~m}$

Chap. 3, 3.9: $v_{1}=17.81 \mathrm{~m} / \mathrm{s}$ and $v_{2}=22.54 \mathrm{~m} / \mathrm{s}$

Chap. 6, 6.4: $Q=1.3 \times 10^{-7} \mathrm{~m}^{3} / \mathrm{s}$ 